\title{
Association between hypertensive pregnancy disorders and future risk of stroke in Taiwan: a Nationwide population- based retrospective case-control study
}

Chun-Chung Huang ${ }^{1 \dagger}$, Chien-Chu Huang ${ }^{2,3+}$, Shao-Yi Lin ${ }^{4}$, Cherry Yin-Yi Chang ${ }^{3,5}$, Wu-Chou Lin ${ }^{3,5}$, Chi-Hsiang Chung ${ }^{6,7}$, Fu-Huang Lin ${ }^{6}$, Chang-Huei Tsao ${ }^{8,9}$, Chun-Min Lo ${ }^{1 *}$ and Wu-Chien Chien ${ }^{8,10,11^{*}}$

\begin{abstract}
Background: The incidence of female stroke has increased gradually and has begun occurring at a younger age in recent years. Given that women live longer than men, stroke would cause more negative and longer-term impacts on the rest of the lives of women. There are few related studies on Asian women. We aimed to evaluate stroke risk in Asian women following hypertensive pregnancy disorders.

Methods: Using the Taiwan National Health Insurance database, we designed a retrospective study that included pregnant women between 2000 and 2013. We selected an age-matched control group of women without hypertensive pregnancy disorders at a 1:3 ratio. The endpoint was any episode of stroke; otherwise, the patients were tracked until December 31, 2013. After the index date until the end of 2013, Cox proportional hazards analysis was used to compare the risk of incident stroke. The risk factors for stroke were determined using Cox proportional regression to calculate the hazard ratio (HR) compared with the control group.

Results: During the follow-up period, the Kaplan-Meier analysis indicated that patients with hypertensive pregnancy disorders had a significantly higher risk of developing stroke than did patients without hypertensive pregnancy disorders (log-rank test $P<0.001$ ). Multivariate Cox regression analysis demonstrated that the case group had a 2.134fold increased risk of stroke $(H R=2.134 ; 95 \% \mathrm{Cl}=1.817-2.505 ; P<0.001)$.

Conclusion: Our study provided evidence of an increased risk of stroke in patients with hypertensive pregnancy disorders. Compared with those without such disorders, the patients who had experienced the disorders had a 2.134fold $(P<0.001)$ higher risk of developing stroke in the future.
\end{abstract}

Keywords: Gestational hypertension, Pre-eclampsia, Eclampsia, Cerebrovascular disease, CVA, Stroke

\footnotetext{
* Correspondence: cmlo@ym.edu.tw; chienwu@mail.ndmctsgh.edu.tw

${ }^{\dagger}$ Chun-Chung Huang and Chien-Chu Huang are co-first authors

'Department of Biomedical Engineering, National Yang-Ming University, 2, Linong St., Beitou Dist, Taipei City 112, Taiwan

${ }^{8}$ Department of Medical Research, Tri-Service General Hospital, National

Defense Medical Center, No.325, Section 2, Cheng-Kung Road, Neihu District,

Taipei City 11490, Taiwan

Full list of author information is available at the end of the article
}

C C The Author(s). 2020 Open Access This article is licensed under a Creative Commons Attribution 4.0 International License, which permits use, sharing, adaptation, distribution and reproduction in any medium or format, as long as you give appropriate credit to the original author(s) and the source, provide a link to the Creative Commons licence, and indicate if changes were made. The images or other third party material in this article are included in the article's Creative Commons licence, unless indicated otherwise in a credit line to the material. If material is not included in the article's Creative Commons licence and your intended use is not permitted by statutory regulation or exceeds the permitted use, you will need to obtain permission directly from the copyright holder. To view a copy of this licence, visit http://creativecommons.org/licenses/by/4.0/. The Creative Commons Public Domain Dedication waiver (http://creativecommons.org/publicdomain/zero/1.0/) applies to the data made available in this article, unless otherwise stated in a credit line to the data. 


\section{Background}

Hypertensive pregnancy disorders are a set of pregnancyspecific systemic diseases with a unique pathophysiology [1-5]. There are three main types of the disease: gestational hypertension, pre-eclampsia-eclampsia, and superimposed pre-eclampsia. Preeclampsia is a multisystem disorder accompanied by the new onset of hypertension and end-organ dysfunction with or without proteinuria. The critical conditions of hypertensive pregnancy disorders include eclampsia, hemolysis, elevated liver enzymes, low platelet counts, and disseminated intravascular coagulopathy [6-9]. Hypertensive pregnancy disorders are critical risk factors for pregnancy-associated stroke [10]. They affect approximately $5 \%$ of pregnant women and increase the risk of pregnancy-associated cerebrovascular disease during the intrapartum and postpartum periods [11-14]. Cerebrovascular dysfunction related to hypertensive pregnancy disorders can lead to stroke, cerebral edema, seizures, and maternal mortality $[10,15,16]$.

A recent study revealed that although women were more likely to survive after stroke, poorer recovery was noted [17]. However, most women did not know they were facing the risk of stroke. According to the JAMA guidelines, an estimated 425,325 new or recurrent strokes occur in women in the United States each year, representing approximately $53.5 \%$ of the stroke population. In 2010, women accounted for approximately $60 \%$ of stroke-related deaths (77,109 of 129,476 deaths). Approximately 3.8 million women live after having a stroke in the United States [18]. Stroke is also the third-leading cause of death in Taiwan, and the mortality rate of stroke was 7.2\% in 2012 [19]. Based on the $1994 \mathrm{Na}$ tional Health Interview Survey, women accounted for approximately $46 \%$ of the stroke population in Taiwan [20]. The related risk factors for stroke included hypertension, diabetes, hyperlipidemia, obesity, atrial fibrillation, and smoking [21-25].

However, few studies have mentioned the association between stroke not occurring during pregnancy or the postpartum period and hypertensive pregnancy disorders [26-29]. Thus, our study determined the risk of future stroke in women in Taiwan with hypertensive pregnancy disorders.

\section{Methods}

\section{Data sources}

The National Health Insurance program was implemented in 1995 in Taiwan, and the National Health Insurance Research Database (NHIRD) records the medical information of all insured people. The database includes approximately 23.74 million people in Taiwan, and it obtained a coverage rate of approximately $99.6 \%$ in 2009 [30, 31]. For study purposes, from 1 million individuals randomly selected as subjects obtained from the
NHIRD, we created a small database. The International Classification of Diseases, Ninth Revision, Clinical Modification (ICD-9-CM) was used for the diagnostic and treatment codes in the NHIRD. With the permission of the National Health Research Institute, our study was able to use the databank. This study was granted approval by the Institutional Review Board of Tri-Service General Hospital (TSGHIRB No. 1-105-05-142).

\section{Study design and sampled participants}

This study was conducted with a retrospective casecontrol design with outpatient and inpatient data. We collected our data from January 1, 2000 to December 31, 2013. Among the 989,753 individuals, 43,675 individuals were diagnosed with hypertensive pregnancy disorders (ICD-9 codes 642.0 to 642.9) prior to the index date. The patients were excluded if they met one of the following criteria: diagnosed with hypertensive pregnancy disorders before the index date, diagnosed with one stroke episode before tracking, aged $<12$ years, and male sex. At the end of the study, the case group comprised 41,870 individuals. A control group matched by index day and age with propensity scores was enrolled at a 3:1 ratio. The same exclusion criteria as that used for the case group was implemented, and the controls did not have hypertensive pregnancy disorder episodes in the study period; 125,610 individuals comprised the control group. The tracking event refers to the occurrence of stroke, and tracking continued until December 31, 2013. Individuals with any diagnoses of cerebrovascular disease (ICD-9 codes: 436.0 to 436.9 and 437.0 to 437.9 ) were defined as being diagnosed with stroke (Fig. 1).

\section{Outcome measures}

All study participants were followed from the index date until the onset of stroke (ICD-9 codes: 436.0 to 436.9 and 437.0 to 437.9 ), withdrawal from the insurance program, or the end of 2013. We eliminated peripartum strokes and postpartum strokes within 3 months (Table S3).

\section{Covariates}

The covariates were age group, area of residence, urbanization level of residence and annual income. The age group was separated into 12-19, 20-29, 30-39, and $\geq 40$ years. The area of residence was divided into northern, central, southern, and eastern regions, as well as surrounding islands. The urbanization level of residence was defined based on multiple indicators of development. Level 1 was defined as a population $>1,250,000$, with more political, economic, cultural and metropolitan development. Level 2 was a population between 500,000 and 1,249,999. Level 4 was populations less than 149, 999, and level 3 was in between levels 2 and 4. The annual income in the United States Dollar (USD) was 


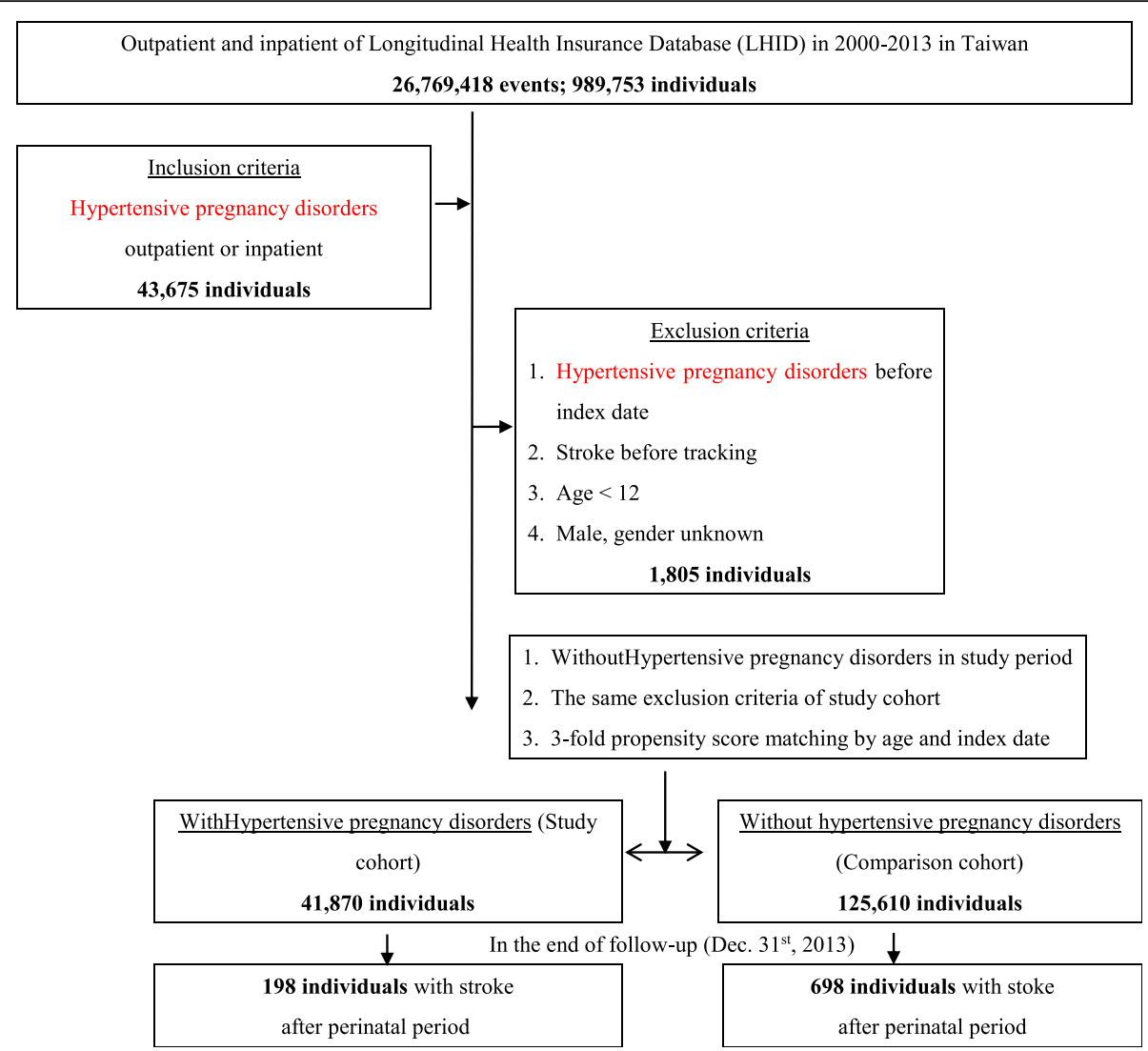

Fig. 1 The flowchart of study sample selection from the National Health Insurance Research Database in Taiwan

separated into three class intervals: $<7200,7200$ to 13 , 999 , and $\geq 14,000$. Regarding the related comorbidities, we included hyperlipidemia (ICD-9 code: 272 ), diabetes mellitus (DM) (ICD-9 code: 250), heart disease (ICD-9 codes: 410-429), hypertension (HTN) (ICD-9 codes: 401-405), chronic kidney disease (CKD) (ICD-9 codes: 274.1, 403-404, 440.1, 442.1, 447.3, 572.4, 580-589, 642.1, and 646.2) and obesity (ICD-9 code: 278).

\section{Statistical analysis}

We conducted the analyses using SPSS 20 software (SPSS, Inc., Chicago, IL, USA). Descriptive statistics were used for basic information, including percentages, average values, and standard deviations.

Differences in the distribution of age, insurance premium, sex, season, location, urbanization level, comorbidities, and level of hospital between the two groups and between subjects with and without stroke were compared using the chi-square test. The Cox proportional hazards regression model was also applied to assess the influence of hypertensive pregnancy disorders on the risk of stroke. The relevant hazard ratios (HRs) and $95 \%$ confidence intervals (CIs) are presented. The difference in stroke risk between the two groups was estimated by the Kaplan-Meier method with the log-rank test. All results were statistically significant if the twotailed $p$ value was less than 0.05 .

\section{Results}

This study examined 41,870 patients with hypertensive pregnancy disorders and 125,610 controls. At the 13year follow-up, the cumulative incidence of stroke was $0.47 \%$ (198/41,870 individuals) in patients with hypertensive pregnancy disorders and $0.56 \%(698 / 125,610$ individuals) in patients without hypertensive pregnancy disorders (Fig. 1 and Table S1). The Kaplan-Meier analysis indicated that patients with hypertensive pregnancy disorders had a significantly higher risk of developing stroke than did patients without hypertensive pregnancy disorders (log-rank test $P<0.001$ ) (Fig. 2). Strokes that occurred during the pregnancy and within 3 months postpartum were eliminated. These strokes were only a small portion of the total burden of disease (Table S3).

In the 13th year of follow-up, the case group was more likely to develop stroke than the control group $(p<$ 0.001). At the end of follow-up, compared to the controls, patients with hypertensive pregnancy disorders tended to be younger in age ( 35.49 years old vs. 36.71 years old; $p<0.001$ ), have lower insurance premiums $(95.48 \%$ vs. $94.77 \% ; p<0.001)$ and have higher rates of 


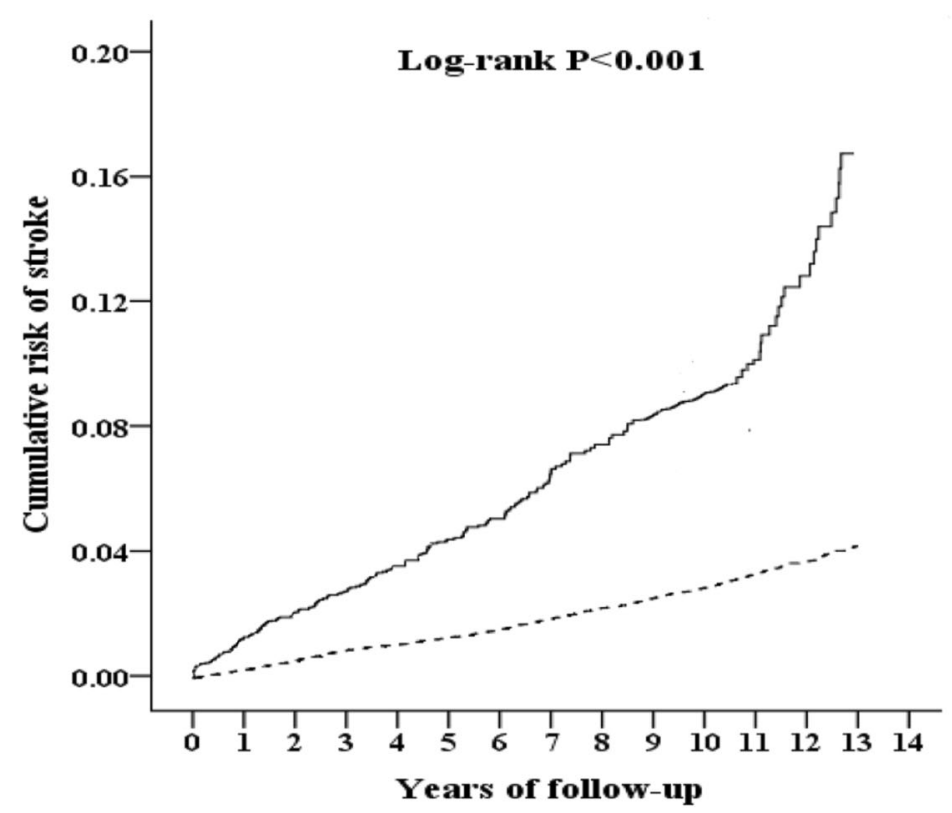

\section{Gestational HTN $\neg$ With $-\tau^{-}$Without} log-rank test

diabetes mellitus $(2.78 \%$ vs. $1.42 \% ; p<0.001)$, HTN (3.29\% vs. $1.37 ; p<0.001)$, and obesity $(0.14 \%$ vs. 0.06 ; $p=0.001)$. Compared to the controls, more patients with hypertensive pregnancy disorders were treated in the hospital center (32.72\% vs. $26.89 \%)$ and regional hospital (37.65\% vs. $32.53 \%)(P<0.001)$ (Table 1$)$.

The Cox regression analysis of the factors associated with the risk of stroke showed that the crude HR was 2.704 (95\% CI $=2.326-3.144, P<0.001)$. After adjusting for the season, the urbanization level of residence and monthly income, the adjusted HR was 2.134 (95\% CI = 1.817-2.505, $P<0.001)$. Compared with younger women (aged 12-19 years old), for women between 20 and 29 and 30-39 years old, the adjusted HRs were $1.306(P<$ $0.001)$ and $1.215(P=0.011)$, respectively. Our results indicated that patients with hypertensive pregnancy disorders had a 2.134-fold higher risk of developing stroke than did individuals without hypertensive pregnancy disorders (Table 2 and S2). Those with diabetes mellitus (DM) $\quad(P<0.001)$, hypertension $($ HTN $) \quad(P<0.001)$, hyperlipidemia $(P<0.001)$, heart disease $(P<0.001)$, and chronic kidney disease $(C K D)(P<0.001)$ had a higher risk of developing stroke than those without these comorbidities. A higher incidence of stroke development was observed among hypertensive pregnancy disorder patients who visited the hospital center than among those who visited the local hospital (Table 2).

The incidence and HR of stroke in populations with or without hypertensive pregnancy disorders relative to those in controls are listed in Table 3. After adjusting for all the other variables, regardless of the other factors, compared with patients without hypertensive pregnancy disorders, those with hypertensive pregnancy disorders had a rate of 1.21 per 1000 patient-years vs. 1.06 per 1000 patient-years in those without gestational hypertension and an $\mathrm{HR}$ of stroke that was 2.134 -fold $(P<0.001)$ higher than that of those without gestational hypertension (Table 3 and Fig. 3).

When we analyzed factors related to stroke and stratified patients by hypertensive pregnancy disorder subgroup using Cox regression, the risk of stroke was 3.412fold (95\% CI $=2.905-4.005)$ higher in patients with a benign essential hypertension-complicated pregnancy (ICD-9: 642.0) $(P<0.001)$, and the rate was 1.9388 per 1000 patient-years. The risk of stroke was 2.130-fold (95\% CI $=1.814-2.500)$ higher in patients with severe preeclampsia (ICD-9: 642.5) $(P<0.001)$, and the rate was 1.2105 per 1000 patient-years. The risk of stroke was 4.584-fold (95\% CI $=3.903-5.380)$ higher in patients with eclampsia (ICD-9: 642.6) $(P<0.001)$, and the rate was 2.6048 per 1000 patient-years. The risk of stroke was 3.117 -fold ( $95 \% \mathrm{CI}=2.654-3.659)$ higher in patients with pre-eclampsia or eclampsia superimposed on preexisting hypertension (ICD-9: 642.7) $(P<0.001)$, and the rate was 1.7712 per 1000 patient-years. The risk of stroke was 2.676 -fold (95\% CI $=2.279-3.141$ ) higher in patients with a hypertension-complicated pregnancy (ICD-9: 642.9) $(P<0.001)$, and the rate was 1.5208 per 1000 patient-years (Fig. 3).

\section{Discussion}

Hypertensive pregnancy disorders are the most common cause of hypertension in pregnant women [5]. They are 
Table 1 Characteristics of the study population in regard to the endpoint

\begin{tabular}{|c|c|c|c|c|c|c|c|}
\hline \multirow{2}{*}{$\begin{array}{l}\text { Hypertensive pregnancy disorders } \\
\text { Variables }\end{array}$} & \multicolumn{2}{|l|}{ Total } & \multicolumn{2}{|l|}{ With } & \multicolumn{2}{|c|}{ Without } & \multirow[t]{2}{*}{$P$} \\
\hline & $\mathrm{n}$ & $\%$ & $n$ & $\%$ & $\mathrm{n}$ & $\%$ & \\
\hline Total & \multicolumn{2}{|l|}{167,480} & 41,870 & 25.00 & 125,610 & 75.00 & \\
\hline \multicolumn{3}{|l|}{ Stroke subgroup } & & & & & $<0.001$ \\
\hline Without & 166,584 & 99.47 & 41,672 & 99.53 & 124,912 & 99.44 & \\
\hline Acute, but ill-defined, cerebrovascular disease & 201 & 0.12 & 80 & 0.19 & 121 & 0.10 & \\
\hline Other and ill-defined cerebrovascular disease & 695 & 0.41 & 118 & 0.28 & 577 & 0.46 & \\
\hline Age (years) & \multicolumn{2}{|c|}{$36.41 \pm 7.07$} & \multicolumn{2}{|c|}{$35.49 \pm 6.44$} & \multicolumn{2}{|c|}{$36.71 \pm 7.28$} & $<0.001$ \\
\hline \multicolumn{7}{|l|}{ Age group (years) } & $<0.001$ \\
\hline $12-19$ & 1645 & 0.98 & 418 & 1.00 & 1227 & 0.98 & \\
\hline $20-29$ & 48,363 & 28.88 & 13,191 & 31.50 & 35,172 & 28.00 & \\
\hline $30-39$ & 90,913 & 54.28 & 22,212 & 53.05 & 68,701 & 54.69 & \\
\hline $40-49$ & 24,790 & 14.80 & 5666 & 13.53 & 19,124 & 15.22 & \\
\hline$\geqq 50$ & 1769 & 1.06 & 383 & 0.91 & 1386 & 1.10 & \\
\hline \multicolumn{7}{|l|}{ Insurance premium (USD) } & $<0.001$ \\
\hline$<7200$ & 159,022 & 94.95 & 39,979 & 95.48 & 119,043 & 94.77 & \\
\hline 7200-13,999 & 7222 & 4.31 & 1511 & 3.61 & 5711 & 4.55 & \\
\hline$\geq 14,000$ & 1236 & 0.74 & 380 & 0.91 & 856 & 0.68 & \\
\hline DM & 2950 & 1.76 & 1165 & 2.78 & 1785 & 1.42 & $<0.001$ \\
\hline HTN & 3096 & 1.85 & 1379 & 3.29 & 1717 & 1.37 & $<0.001$ \\
\hline Hyperlipidemia & 893 & 0.53 & 312 & 0.75 & 581 & 0.46 & 0.224 \\
\hline Obesity & 129 & 0.08 & 59 & 0.14 & 70 & 0.06 & 0.001 \\
\hline Heart disease & 2708 & 1.62 & 684 & 1.63 & 2024 & 1.61 & 0.892 \\
\hline CKD & 1394 & 0.83 & 377 & 0.90 & 1017 & 0.81 & 0.794 \\
\hline \multicolumn{7}{|l|}{ Season } & $<0.001$ \\
\hline Spring & 36,206 & 21.62 & 9454 & 22.58 & 26,752 & 21.30 & \\
\hline Summer & 47,389 & 28.30 & 10,265 & 24.52 & 37,124 & 29.55 & \\
\hline Autumn & 41,478 & 24.77 & 11,104 & 26.52 & 30,374 & 24.18 & \\
\hline Winter & 42,407 & 25.32 & 11,047 & 26.38 & 31,360 & 24.97 & \\
\hline \multicolumn{7}{|l|}{ Location } & $<0.001$ \\
\hline Northern Taiwan & 67,388 & 40.24 & 17,254 & 41.21 & 50,134 & 39.91 & \\
\hline Middle Taiwan & 43,559 & 26.01 & 10,134 & 24.20 & 33,425 & 26.61 & \\
\hline Southern Taiwan & 40,128 & 23.96 & 10,004 & 23.89 & 30,124 & 23.98 & \\
\hline Eastern Taiwan & 15,413 & 9.20 & 4101 & 9.79 & 11,312 & 9.01 & \\
\hline Surrounding islands & 992 & 0.59 & 377 & 0.90 & 615 & 0.49 & \\
\hline \multicolumn{7}{|l|}{ Urbanization level } & $<0.001$ \\
\hline 1 (The highest) & 63,431 & 37.87 & 15,297 & 36.53 & 48,134 & 38.32 & \\
\hline 2 & 75,770 & 45.24 & 19,784 & 47.25 & 55,986 & 44.57 & \\
\hline 3 & 10,955 & 6.54 & 2111 & 5.04 & 8844 & 7.04 & \\
\hline 4 (The lowest) & 17,324 & 10.34 & 4678 & 11.17 & 12,646 & 10.07 & \\
\hline \multicolumn{7}{|l|}{ Level of care } & $<0.001$ \\
\hline Hospital center & 47,476 & 28.35 & 13,701 & 32.72 & 33,775 & 26.89 & \\
\hline Regional hospital & 56,621 & 33.81 & 15,765 & 37.65 & 40,856 & 32.53 & \\
\hline Local hospital & 63,383 & 37.85 & 12,404 & 29.63 & 50,979 & 40.59 & \\
\hline
\end{tabular}

$P:$ Chi-square/Fisher exact test for categorical variables and t-test for continuous variables 
Table 2 Factors associated with stroke according to Cox regression

\begin{tabular}{|c|c|c|c|c|c|c|c|c|}
\hline Variables & Crude HR & $95 \% \mathrm{Cl}$ & $95 \% \mathrm{Cl}$ & $P$ & Adjusted HR & $95 \% \mathrm{Cl}$ & $95 \% \mathrm{Cl}$ & $P$ \\
\hline \multicolumn{9}{|c|}{ Hypertensive pregnancy disorders } \\
\hline Without & Reference & & & & Reference & & & \\
\hline With & 2.704 & 2.326 & 3.144 & $<0.001$ & 2.134 & 1.817 & 2.505 & $<0.001$ \\
\hline \multicolumn{9}{|l|}{ Age group (years) } \\
\hline $12-19$ & Reference & & & & Reference & & & \\
\hline $20-29$ & 1.105 & 1.048 & 1.261 & 0.029 & 1.306 & 1.137 & 1.942 & $<0.001$ \\
\hline $30-39$ & 1.129 & 1.060 & 1.278 & 0.024 & 1.215 & 1.087 & 1.320 & 0.011 \\
\hline $40-49$ & 1.094 & 0.452 & 1.413 & 0.367 & 1.285 & 0.913 & 1.248 & 0.218 \\
\hline$\geqq 50$ & 0.341 & 0.158 & 1.012 & 0.055 & 0.537 & 0.084 & 1.065 & 0.066 \\
\hline \multicolumn{9}{|c|}{ Insured premium (USD) } \\
\hline$<7200$ & Reference & & & & Reference & & & \\
\hline 7200-13,999 & 1.458 & 0.149 & 2.271 & 0.224 & 1.966 & 0.522 & 2.582 & 0.249 \\
\hline$\geq 14,000$ & 1.755 & 0.447 & 2.425 & 0.124 & 2.650 & 0.157 & 4.762 & 0.179 \\
\hline DM & 4.190 & 3.532 & 4.970 & $<0.001$ & 1.449 & 1.277 & 1.874 & $<0.001$ \\
\hline HTN & 7.696 & 6.742 & 8.903 & $<0.001$ & 4.274 & 3.616 & 5.050 & $<0.001$ \\
\hline Hyperlipidemia & 8.175 & 6.559 & 10.177 & $<0.001$ & 3.061 & 2.415 & 3.886 & $<0.001$ \\
\hline Obesity & 2.607 & 0.910 & 6.490 & 0.067 & 1.115 & 0.418 & 2.995 & 0.584 \\
\hline Heart disease & 4.027 & 3.353 & 4.837 & $<0.001$ & 2.136 & 1.761 & 2.589 & $<0.001$ \\
\hline CKD & 4.444 & 3.466 & 5.699 & $<0.001$ & 2.356 & 1.829 & 3.041 & $<0.001$ \\
\hline 4 (The lowest) & Reference & & & & Reference & & & \\
\hline \multicolumn{9}{|l|}{ Level of care } \\
\hline Hospital center & 1.876 & 1.592 & 2.213 & $<0.001$ & 1.631 & 1.349 & 1.972 & $<0.001$ \\
\hline Regional hospital & 1.209 & 1.020 & 1.436 & 0.011 & 2.133 & 0.885 & 1.251 & 0.242 \\
\hline Local hospital & Reference & & & & Reference & & & \\
\hline
\end{tabular}

HR hazard ratio, $\mathrm{Cl}$ confidence interval, Adjusted HR: Adjusted for variables listed in the table Adjusted variables: geographical area of residence, urbanization level of residence, and season

classified into 3 categories: gestational hypertension, preeclampsia-eclampsia, and superimposed preeclampsia [32]. Women with chronic high blood pressure experience more complications during pregnancy [12]. High blood pressure may also lead to other long-term health problems after pregnancy. Stroke is an undesirable condition among younger women, as it is considered to have adverse effects on personal status, families and society. Health issues not only affect women but also demand major changes of the whole family. The incidences of both early- and late-onset preeclampsia increased in Taiwan from 2001 to 2014, especially for early-onset disease [33]. Preeclampsia has become an important issue to be aware of.

Studies show that hypertensive pregnancy disorders not only affect the pregnancy period but also increase the risk of cardiovascular disease later in life [34, 35]. Pregnancy-related hypertension is thought to be an important risk factor for both cerebrovascular disease and intracranial venous thrombosis in some studies [36]. One study based on the general population during the intrapartum and postpartum periods in Taiwan revealed that preeclampsia/eclampsia are the two most common causes of intracranial hemorrhage and the three most common causes of cerebral infarction during the intrapartum and postpartum periods [37].

In one cohort study in Sweden, the authors found that an increased risk of cardiovascular disease and cerebrovascular disease after hypertensive disease of pregnancy persisted in the older population [21]. One study in Taiwan previously revealed that the respective adjusted relative risk of hemorrhagic and ischemic cerebrovascular disease after preeclampsia-eclampsia was much higher, regardless of whether it was within the first 3 days postpartum or within 1 year of the postpartum period [38]. One retrospective cohort study based on the Utah Population Database also showed that women with hypertensive disease of pregnancy have increased 
Table 3 Factors associated with stroke stratified by variables listed in the table by using Cox regression

\begin{tabular}{|c|c|c|c|c|c|c|c|c|c|c|c|}
\hline \multirow{2}{*}{$\begin{array}{l}\text { Hypertensive pregnancy disorders } \\
\text { Stratified }\end{array}$} & \multicolumn{3}{|l|}{ With } & \multicolumn{3}{|c|}{ Without (Reference) } & \multirow[t]{2}{*}{ Ratio } & \multirow{2}{*}{$\begin{array}{l}\text { Adjusted } \\
\text { HR }\end{array}$} & \multirow{2}{*}{$\begin{array}{l}95 \% \\
\mathrm{Cl}\end{array}$} & \multirow{2}{*}{$\begin{array}{l}95 \% \\
\mathrm{Cl}\end{array}$} & \multirow[t]{2}{*}{$P$} \\
\hline & Events & PYs & $\begin{array}{l}\text { Rate } \\
\text { (per } 10^{5} \mathrm{PYs} \text { ) }\end{array}$ & Events & PYs & $\begin{array}{l}\text { Rate } \\
\text { (per } 10^{5} \mathrm{PYs} \text { ) }\end{array}$ & & & & & \\
\hline Total & 198 & $163,208.79$ & 121.32 & 698 & $654,982.30$ & 106.57 & 1.138 & 2.134 & 1.817 & 2.505 & $<0.001$ \\
\hline \multicolumn{12}{|l|}{ Age group (years) } \\
\hline $12-19$ & 2 & 271.80 & 735.83 & 3 & 589.64 & 508.78 & 1.446 & 2.711 & 2.308 & 3.182 & $<0.001$ \\
\hline $20-29$ & 64 & $32,914.98$ & 194.44 & 87 & $80,370.21$ & 108.25 & 1.796 & 3.367 & 2.867 & 3.953 & $<0.001$ \\
\hline $30-39$ & 97 & $77,048.17$ & 125.90 & 303 & $238,213.86$ & 127.20 & 0.990 & 1.855 & 1.580 & 2.178 & $<0.001$ \\
\hline $40-49$ & 34 & $18,003.53$ & 188.85 & 294 & $137,974.59$ & 213.08 & 0.886 & 1.661 & 1.415 & 1.950 & $<0.001$ \\
\hline$\geqq 50$ & 1 & $34,970.30$ & 2.86 & 11 & $197,833.99$ & 5.56 & 0.514 & 0.964 & 0.821 & 1.132 & 0.276 \\
\hline \multicolumn{12}{|l|}{ Insured premium (USD) } \\
\hline$<7200$ & 191 & $125,404.75$ & 152.31 & 688 & $466,665.85$ & 147.43 & 1.033 & 1.937 & 1.649 & 2.273 & $<0.001$ \\
\hline 7200-13,999 & 5 & 2344.91 & 213.23 & 8 & 8975.42 & 89.13 & 2.392 & 4.484 & 3.818 & 5.264 & $<0.001$ \\
\hline$\geq 14,000$ & 2 & $35,459.13$ & 5.64 & 2 & $179,341.03$ & 1.12 & 5.058 & 9.481 & 8.073 & 11.129 & $<0.001$ \\
\hline DM & 20 & 8430.94 & 237.22 & 56 & $42,672.99$ & 131.23 & 1.808 & 3.389 & 2.885 & 3.978 & $<0.001$ \\
\hline HTN & 54 & $13,688.23$ & 394.50 & 99 & $35,172.46$ & 281.47 & 1.402 & 2.627 & 2.237 & 3.084 & $<0.001$ \\
\hline Hyperlipidemia & 13 & 1980.06 & 656.55 & 42 & 8226.33 & 510.56 & 1.286 & 2.411 & 2.052 & 2.830 & $<0.001$ \\
\hline Obesity & 1 & 477.68 & 209.35 & 1 & 2343.45 & 42.67 & 4.906 & 9.196 & 7.830 & 10.795 & $<0.001$ \\
\hline Heart disease & 14 & 5039.75 & 277.79 & 75 & $33,325.22$ & 225.05 & 1.234 & 2.314 & 1.970 & 2.716 & $<0.001$ \\
\hline CKD & 6 & 2500.94 & 239.91 & 40 & $23,770.74$ & 168.27 & 1.426 & 2.673 & 2.276 & 3.137 & $<0.001$ \\
\hline \multicolumn{12}{|l|}{ Season } \\
\hline Spring & 52 & $30,039.53$ & 173.11 & 146 & $109,482.26$ & 133.35 & 1.298 & 2.433 & 2.072 & 2.856 & $<0.001$ \\
\hline Summer & 40 & $32,853.28$ & 121.75 & 175 & $126,710.16$ & 138.11 & 0.882 & 1.653 & 1.407 & 1.940 & $<0.001$ \\
\hline Autumn & 61 & $37,155.10$ & 164.18 & 191 & $132,193.49$ & 144.49 & 1.136 & 2.130 & 1.814 & 2.500 & $<0.001$ \\
\hline Winter & 45 & $63,160.87$ & 71.25 & 186 & $286,596.39$ & 64.90 & 1.098 & 2.058 & 1.752 & 2.416 & $<0.001$ \\
\hline \multicolumn{12}{|l|}{ Urbanization level } \\
\hline 1 (The highest) & 75 & $43,701.39$ & 171.62 & 225 & $153,595.67$ & 146.49 & 1.172 & 2.196 & 1.870 & 2.578 & $<0.001$ \\
\hline 2 & 83 & $57,996.46$ & 143.11 & 294 & $210,128.07$ & 139.91 & 1.023 & 1.917 & 1.633 & 2.251 & $<0.001$ \\
\hline 3 & 16 & $10,060.20$ & 159.04 & 40 & $46,748.29$ & 85.56 & 1.859 & 3.484 & 2.967 & 4.090 & $<0.001$ \\
\hline 4 (The lowest) & 24 & $51,450.75$ & 46.65 & 139 & $244,510.27$ & 56.85 & 0.821 & 1.538 & 1.310 & 1.806 & $<0.001$ \\
\hline \multicolumn{12}{|l|}{ Level of care } \\
\hline Hospital center & 96 & $43,471.31$ & 220.84 & 301 & $142,056.49$ & 211.89 & 1.042 & 1.954 & 1.663 & 2.293 & $<0.001$ \\
\hline Regional hospital & 64 & $50,293.76$ & 127.25 & 215 & $183,114.94$ & 117.41 & 1.084 & 2.032 & 1.730 & 2.385 & $<0.001$ \\
\hline Local hospital & 38 & $69,443.72$ & 54.72 & 182 & $329,810.87$ & 55.18 & 0.992 & 1.859 & 1.583 & 2.182 & $<0.001$ \\
\hline
\end{tabular}

PYS Person-years; Adjusted HR Adjusted hazard ratio: Adjusted for the variables listed in Table 3; Cl confidence interval

mortality risk, particularly with respect to ischemic heart disease and cerebrovascular disease [39].

Our study revealed an important issue in hypertensive pregnancy disorders during pregnancy. Strokes that did not occur in the pregnancy and postpartum timeframes accounted for a main portion of the total burden of disease. Women with hypertensive disorders of pregnancy are at significant risk for stroke at a relatively young age. Interval hypertension control and follow-up after pregnancy is likely to be important. Patient education on future stroke issues, exercise and diet counseling could be involved in the postpartum period. Women with a history of hypertensive pregnancy disorders should be candidates for risk modification, including HTN control, lipid management, and weight management.

Our study included a well-established dataset using population-based research with a large sample size, and we explored hypertensive pregnancy disorders as a risk factor for developing stroke. Nevertheless, there are still some limitations of this study. First, although the coding of the NHIRD has not been validated in the recording of all diseases, there were no reports regarding the coding 


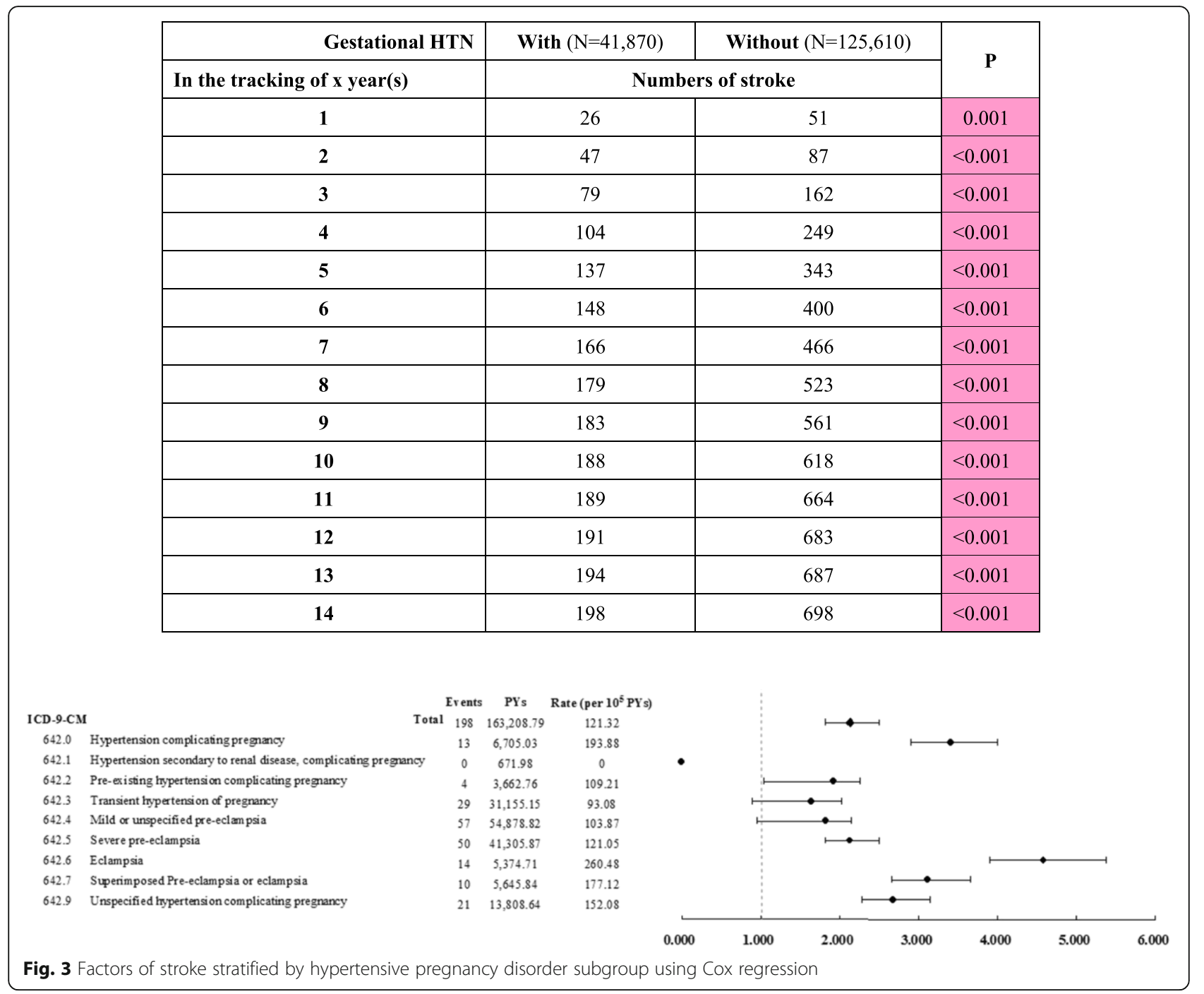

of the severity of stroke or the location of stroke. Data on blood pressure during pregnancy and the control status of hypertensive pregnancy disorders were also unavailable in the database. For these reasons, the effect of hypertensive pregnancy disorders on the severity of stroke or the site of stroke could not be analyzed in detail. Second, the NHIRD registry cannot provide detailed information regarding patients' laboratory results, lifestyles, past history or family history, and we believe some of these factors, such as smoking, may increase the risk of stroke. Third, given that the population comprises younger females, there might be an underlying disease of the brain that was not noted before, and although the population may be small, we believed that it could also contribute to the increased incidence of stroke [40]. Fourth, there are also some factors that may contribute to stroke, such as autoimmune diseases [41-
43], thyroid disease [43-45], oral contraceptive use [4648], and infectious diseases [49-51], none of which were discussed in this study.

\section{Conclusions}

Our study provided evidence of the increased risk of stroke in patients with hypertensive pregnancy disorders. Compared with those without hypertensive pregnancy disorders, the patients who had experienced such disorders had a 2.134-fold $(P<0.001)$ higher risk of developing stroke in the future. The occurrence of stroke in younger women is an important issue, especially among those who are in the childbearing stage. The results from this study will provide physicians with strong proof of the need for the cautious treatment of patients with hypertensive pregnancy disorders and awareness of possible future stroke problems. 


\section{Supplementary information}

Supplementary information accompanies this paper at https://doi.org/10. 1186/s12884-020-02898-9.

Additional file 1: Table S1. Distribution of hypertensive pregnancy disorders. Table S2. Factors (season, location, urbanization level) associated with stroke using Cox regression. Table S3. Sensitivity of factors associated with stroke by using Cox regression.

\section{Abbreviations}

CVA: Cerebrovascular accident; HR: Hazard ratio; JAMA: Journal of the American Medical Association; NHIRD: National Health Insurance Research Database; ICD-9-CM: International Classification of Diseases, Ninth Revision, and Clinical Modification; HTN: Hypertension; USD: United States Dollar; DM: Diabetes mellitus; CKD: Chronic kidney disease; Cls: Confidence intervals

\section{Acknowledgements}

Not applicable

\section{Authors' contributions}

All authors have read and approved the manuscript. Chun-C. Huang: substantial contributions to the conception and design of the study, the interpretation of data, and the drafting and revision of the paper. Chien-C. Huang: substantial contributions to the conception and design of the study, the interpretation of data, and the drafting and revision of the paper. S.Y. Lin: substantial contributions to the conception of the paper, the interpretation of data and the drafting of the paper. Cherry Y.Y. Chang: substantial contributions to the conception of the study and the interpretation of data. W.C. Lin: substantial contributions to the conception of the study and the interpretation of data. C.H. Chung: substantial contributions to the conception and design of the study and the acquisition and analysis of the data. F.H. Lin: substantial contributions to the conception and design of the study and the acquisition and analysis of the data. C.H. Tsao: substantial contributions to the conception and design of the study and the acquisition and analysis of the data. C.M. Lo: substantial contributions to the conception and design of the study; the acquisition, analysis, and interpretation of data; and the drafting and revision of the paper. W.C. Chien: substantial contributions to the conception and design of the study; the acquisition, analysis, and interpretation of data; and the drafting and revision of the paper. Final approval of manuscript: All authors.

\section{Funding}

This study was funded by the Tri-Service General Hospital Research Foundation (TSGH-B-109-010). The funder played no role in the design; conception; data collection, interpretation, and analysis; drafting; or any other process in this paper.

\section{Availability of data and materials}

The data that support the findings of this study are available from the National Health Insurance Research Database (NHIRD) in Taiwan, but restrictions apply regarding the availability of these data, which were used under license for the current study and thus are not publicly available. The data are, however, available from the authors upon reasonable request and with permission of the National Health Insurance Research Database (NHIRD) in Taiwan.

\section{Ethics approval and consent to participate}

Institutional Review Board of Tri-Service General Hospital (TSGHIRB No. 1105-05-142).

\section{Consent for publication}

Not applicable.

\section{Competing interests}

The authors declare that they have no competing interests.

\section{Author details}

${ }^{1}$ Department of Biomedical Engineering, National Yang-Ming University, 2, Linong St., Beitou Dist, Taipei City 112, Taiwan. ${ }^{2}$ Graduate Institution of Biomedical Sciences, China Medical University, No. 2, Yuh-Der Road,
Taichung 404, Taiwan. ${ }^{3}$ Department of Obstetrics and Gynecology, China Medical University Hospital, Taichung, Taiwan. ${ }^{4}$ Department of Mechanical and Computer-Aided Engineering, National Formosa University, No. 64, Wunhua Rd, Huwei Township, Yunlin County 632, Taiwan. ${ }^{5}$ Department of Medicine, China Medical University, No. 2, Yuh-Der Road, Taichung 404 Taiwan. ${ }^{6}$ School of Public Health, National Defense Medical Center, No. 325, Section 2, Cheng-Kung Road, Neihu District, Taipei City 11490, Taiwan. ${ }^{7}$ Taiwanese Injury Prevention and Safety Promotion Association (TIPSPA), No. 325, Section 2, Cheng-Kung Road, Neihu District, Taipei City 11490, Taiwan. ${ }^{8}$ Department of Medical Research, Tri-Service General Hospital, National Defense Medical Center, No.325, Section 2, Cheng-Kung Road, Neihu District, Taipei City 11490, Taiwan. ${ }^{9}$ Department of Microbiology \& Immunology, National Defense Medical Center, No. 325, Section 2, Cheng-Kung Road, Neihu District, Taipei City 11490, Taiwan. ${ }^{10}$ Graduate Institute of Life Sciences, National Defense Medical Center, Taipei City, Taiwan. ${ }^{11}$ School of Public Health, National Defense Medical Center, Taipei City, Taiwan.

Received: 11 January 2019 Accepted: 27 March 2020

Published online: 15 April 2020

\section{References}

1. Pijnenborg R, ANTHONY J, DAVEY DA, REES A, TILTMAN A, VERCRUYSSE L, et al. Placental bed spiral arteries in the hypertensive disorders of pregnancy. BJOG Int J Obstet Gynaecol. 1991;98(7):648-55.

2. Grobe JL, Santillan MK, Santillan DA. Early prediction of preeclampsia. Google Patents; 2017.

3. Thornton C, Tooher J, Ogle R, von Dadelszen P, Makris A, Hennessy A. Benchmarking the hypertensive disorders of pregnancy. Pregnancy Hypertens 2016;6(4):279-284. PubMed PMID: 27939468.

4. Moatti Z, Gupta M, Yadava R, Thamban S. A review of stroke and pregnancy: incidence, management and prevention. Eur J Obstet Gynecol Reprod Biol 2014;181:20-27. PubMed PMID: 25124706.

5. Brown MA, Lindheimer MD, de Swiet M, Assche AV, Moutquin J-M. The classification and diagnosis of the hypertensive disorders of pregnancy: statement from the International Society for the Study of hypertension in pregnancy (ISSHP). Taylor \& Francis; 2001.

6. Frontera JA, Ahmed W. Neurocritical care complications of pregnancy and puerperum. J Crit Care 2014;29(6):1069-1081. PubMed PMID: 25123793.

7. Dasgupta NR, Guzman LA, Chapman DB. Pre-eclampsia associated with carotid dissection and stroke in a young woman. J Stroke Cerebrovasc Dis 2010;19(2):163-164. PubMed PMID: 20189093.

8. Shainker SA, Edlow JA, O'Brien K. Cerebrovascular emergencies in pregnancy. Best Pract Res Clin Obstet Gynaecol 2015;29(5):721-731. PubMed PMID: 25890883.

9. Walker JJ. Severe pre-eclampsia and eclampsia. Bailliere's Best Pract Res Clin Obstet Gynaecol 2000;14(1):57-71. PubMed PMID: 10789260.

10. Mackay AP, Berg CJ, Atrash HK. Pregnancy-related mortality from preeclampsia and eclampsia. Obstet Gynecol. 2001:97(4):533-8.

11. Miller EC, Gatollari HJ, Too G, Boehme AK, Leffert L, Marshall RS, et al Risk factors for pregnancy-associated stroke in women with preeclampsia. Stroke 2017:48(7):1752-1759. PubMed PMID: 28546324. Pubmed Central PMCID: 5539968.

12. Duley L. Maternal mortality associated with hypertensive disorders of pregnancy in Africa, Asia, Latin America and the Caribbean. BJOG Int J Obstet Gynaecol. 1992;99(7):547-53.

13. Irgens HU, Reisaeter L, Irgens LM, Lie RT. Long term mortality of mothers and fathers after pre-eclampsia: population based cohort study. Bmj. 2001; 323(7323):1213-1217. PubMed PMID: 11719411. Pubmed Central PMCID: 59993.

14. Jarvie JL, Metz TD, Davis MB, Ehrig JC, Kao DP. Short-term risk of cardiovascular readmission following a hypertensive disorder of pregnancy. Heart 2018;104(14):1187-1194. PubMed PMID: 29326108.

15. Hammer ES, Cipolla MJ. Cerebrovascular dysfunction in Preeclamptic pregnancies. Curr Hypertens Rep 2015;17(8):64. PubMed PMID: 26126779. Pubmed Central PMCID: 4752117

16. Cunningham FG. Severe preeclampsia and eclampsia: systolic hypertension is also important. Obstet Gynecol 2005;105(2):237-238. PubMed PMID: 15684145

17. Carcel C, Wang X, Sandset EC, Delcourt C, Arima H, Lindley R, et al. Sex differences in treatment and outcome after stroke: pooled analysis including 19,000 participants. Neurology. 2019;93(24):e2170-e80. 
18. Mitka M New guidelines focus on preventing stroke in women. Jama 2014; 311(10):1003-1004. PubMed PMID: 24618946.

19. Hsieh F-I, Chiou H-Y. Stroke: morbidity, risk factors, and care in Taiwan. J Stroke. 2014;16(2):59.

20. Huang Z-S, Chiang T-L, Lee T-K. Stroke prevalence in Taiwan: findings from the 1994 national health interview survey. Stroke. 1997:28(8):1579-84.

21. Nelander M, Cnattingius S, Akerud H, Wikstrom J, Pedersen NL, Wikstrom AK. Pregnancy hypertensive disease and risk of dementia and cardiovascular disease in women aged 65 years or older: a cohort study. BMJ Open 2016; 6(1):e009880. PubMed PMID: 26801467. Pubmed Central PMCID: 4735184.

22. Rexrode KM, Hennekens CH, Willett WC, Colditz GA, Stampfer MJ, RichEdwards JW, et al. A prospective study of body mass index, weight change, and risk of stroke in women. Jama. 1997;277(19):1539-45.

23. Fung TT, Stampfer MJ, Manson JE, Rexrode KM, Willett WC, Hu FB. Prospective study of major dietary patterns and stroke risk in women. Stroke. 2004;35(9):2014-9.

24. Stampfer MJ, Colditz GA, Willett WC, Speizer FE, Hennekens CH. A prospective study of moderate alcohol consumption and the risk of coronary disease and stroke in women. N Engl J Med. 1988;319(5):267-73.

25. Wolf PA, Abbott RD, Kannel WB. Atrial fibrillation as an independent risk factor for stroke: the Framingham study. Stroke. 1991;22(8):983-8.

26. Brown DW, Dueker N, Jamieson DJ, Cole JW, Wozniak MA, Stern BJ, et al Preeclampsia and the risk of ischemic stroke among young women: results from the stroke prevention in young women study. Stroke 2006;37(4):10551059. PubMed PMID: 16484606.

27. Dayan N, Kaur A, Elharram M, Rossi AM, Pilote L. Impact of preeclampsia on long-term cognitive function. Hypertension 2018;72(6):1374-1380. PubMed PMID: 30571227.

28. Coutinho T, Lamai O, Nerenberg K. Hypertensive disorders of pregnancy and cardiovascular diseases: current knowledge and future directions. Curr Treat Options Cardiovasc Med 2018;20(7):56. PubMed PMID: 29923067.

29. Cipolla MJ, Liebeskind DS, Chan SL. The importance of comorbidities in ischemic stroke: impact of hypertension on the cerebral circulation. J Cerebral Blood Flow Metab 2018;38(12):2129-2149. PubMed PMID: 30198826. Pubmed Central PMCID: 6282213.

30. Cheng T-M. Taiwan's National Health Insurance system: high value for the dollar. Six countries, six reform models: the healthcare reform experience of Israel, the Netherlands, New Zealand, Singapore, Switzerland and Taiwan: healthcare reforms "under the radar screen": World Scientific; 2010. p. 171-204.

31. Okma KG. Six countries, six reform models: the healthcare reform experience of Israel, the Netherlands, New Zealand, Singapore, Switzerland and Taiwanhealthcare reforms under the radar screen: world scientific; 2009.

32. Barton JR, O'Brien JM, Bergauer NK, Jacques DL, Sibai BM. Mild gestational hypertension remote from term: progression and outcome. Am J Obstet Gynecol. 2001;184(5):979-83.

33. You SH, Cheng PJ, Chung TT, Kuo CF, Wu HM, Chu PH. Population-based trends and risk factors of early- and late-onset preeclampsia in Taiwan 20012014. BMC Pregnancy Childbirth 2018;18(1):199. PubMed PMID: 29855344. Pubmed Central PMCID: 5984409.

34. Stuart JJ, Tanz $\amalg$, Cook NR, Spiegelman D, Missmer SA, Rimm EB, et al Hypertensive disorders of pregnancy and 10-year cardiovascular risk prediction. J Am Coll Cardiol 2018;72(11):1252-1263. PubMed PMID: 30190003. Pubmed Central PMCID: 6136445

35. Theilen LH, Meeks H, Fraser A, Esplin MS, Smith KR, Varner MW. Long-term mortality risk and life expectancy following recurrent hypertensive disease of pregnancy. American journal of obstetrics and gynecology. $2018 \mathrm{Jul}$; 219(1):107 e1- e6. PubMed PMID: 29630888. Pubmed Central PMCID: 6019643.

36. Lanska DJ, Kryscio RJ. Risk factors for peripartum and postpartum stroke and intracranial venous thrombosis. Stroke 2000;31(6):1274-1282. PubMed PMID: 10835444.

37. Liang CC, Chang SD, Lai SL, Hsieh CC, Chueh HY, Lee TH. Stroke complicating pregnancy and the puerperium. Eur J Neurol 2006;13(11): 1256-1260. PubMed PMID: 17038042.

38. Tang CH, Wu CS, Lee TH, Hung ST, Yang CY, Lee CH, et al Preeclampsiaeclampsia and the risk of stroke among peripartum in Taiwan. Stroke 2009; 40(4):1162-1168. PubMed PMID: 19228854.

39. Theilen LH, Fraser A, Hollingshaus MS, Schliep KC, Varner MW, Smith KR, et al All-cause and cause-specific mortality after hypertensive disease of pregnancy. Obstet Gynecol 2016;128(2):238-244. PubMed PMID: 27400006. Pubmed Central PMCID: 4961555.
40. Burke GL, Evans GW, Riley WA, Sharrett AR, Howard G, Barnes RW, et al. Arterial wall thickness is associated with prevalent cardiovascular disease in middle-aged adults. Stroke. 1995;26(3):386-91.

41. Ward MM. Premature morbidity from cardiovascular and cerebrovascular diseases in women with systemic lupus erythematosus. Arthritis Rheumatol. 1999;42(2):338-46.

42. Walsh SJ, Rau LM. Autoimmune diseases: a leading cause of death among young and middle-aged women in the United States. Am J Public Health. 2000;90(9):1463.

43. Karch A, Thomas SL. Autoimmune thyroiditis as a risk factor for stroke a historical cohort study. Neurology. 2014;82(18):1643-52.

44. Squizzato A, Gerdes V, Brandjes D, Büller H, Stam J. Thyroid diseases and cerebrovascular disease. Stroke. 2005;36(10):2302-10.

45. Grossman A, Weiss A, Koren-Morag N, Shimon I, Beloosesky Y, Meyerovitch J. Subclinical thyroid disease and mortality in the elderly: a retrospective cohort study. Am J Med. 2016;129(4):423-30.

46. Vessey M, Doll R. Investigation of relation between use of oral contraceptives and thromboembolic disease. Br Med J. 1968;2(5599):199.

47. Stampfer MJ, Willett WC, Colditz GA, Speizer FE, Hennekens CH. A prospective study of past use of oral contraceptive agents and risk of cardiovascular diseases. N Engl J Med. 1988;319(20):1313-7.

48. Bezemer ID, Verhamme KM, Gini R, Mosseveld M, Rijnbeek PR, Trifirò G, et al. Use of oral contraceptives in three European countries: a population-based multi-database study. Eur J Contracept Reprod Health Care. 2016;21(1):81-7.

49. Wimmer ML, Sandmann-Strupp R, Saikku P, Haberl RL. Association of chlamydial infection with cerebrovascular disease. Stroke. 1996;27(12):2207-10.

50. Markus HS, Mendall MA. Helicobacter pylori infection: a risk factor for ischaemic cerebrovascular disease and carotid atheroma. J Neurol Neurosurg Psychiatry. 1998;64(1):104-7.

51. Lindsberg PJ, Grau AJ. Inflammation and infections as risk factors for ischemic stroke. Stroke. 2003;34(10):2518-32.

\section{Publisher's Note}

Springer Nature remains neutral with regard to jurisdictional claims in published maps and institutional affiliations.

\section{Ready to submit your research? Choose BMC and benefit from:}

- fast, convenient online submission

- thorough peer review by experienced researchers in your field

- rapid publication on acceptance

- support for research data, including large and complex data types

- gold Open Access which fosters wider collaboration and increased citations

- maximum visibility for your research: over $100 \mathrm{M}$ website views per year

At $\mathrm{BMC}$, research is always in progress.

Learn more biomedcentral.com/submissions 